\title{
Consideration and Expectation on the Establishment of Application-oriented Universities by Civil-run Colleges
}

\author{
Ming Sun \\ Zhuhai College of Jilin University \\ Zhuhai, China
}

\author{
Jingchuan $\mathrm{Fu}$ \\ Zhuhai College of Jilin University \\ Zhuhai, China
}

\begin{abstract}
During the period of " $13^{\text {th }}$ Five-year Plan", in the course of local establishment of application-oriented universities, civil-run colleges have aroused the extensive public attention with vigorous support from government and enterprises, thus making it in line with public colleges for the first time. The transformation development of civil-run colleges cannot be possible without the active adaptation to local innovation-driven strategy and the transfusion of talents, technologies and intellectual supports for the benefit of local economic and social development. Civil-run colleges should change their idea of school running, start with the reform of innovation and entrepreneurship education, enhance the competence of high-level scientific research in satisfying the first-line needs, build a proficient "double-qualified teacher" team, exploit various resources, make full use of their own advantages and characteristics, and establish themselves as high-level application-oriented universities.
\end{abstract}

Keywords-civil-run colleges; application-oriented universities; transformation

\section{INTRODUCTION}

On October $25^{\text {th }}$, Guangdong Provincial Department of Education issued the list of "Guangdong General Pilot Colleges for Education Transformation", 14 provincial colleges were selected as the first pilot colleges, in which Zhuhai College of Jilin University was announced to be one of the six civil-run colleges, along with public colleges listed in the first pilot sites of Guangdong application-oriented college establishment. During the period of " $13^{\text {th }}$ Five-year Plan", in the course of application-oriented college establishment vigorously promoted by state and local government, civil-run colleges have been given the support and attention at the level that is never seen before, how to establish an application-oriented university? How to make full use of advantages and highlight our own characteristics in the transformation development? How to evolve into a strong prop to serve the local economic and social development? Such questions become the major challenge

\section{Supported Projects:}

1. Fu Jingchuan. Development plan of application-oriented universities in the context of innovation-driven strategy during the "13th five-year plan" (Guangdong Provincial Department of Education, The 2015 Provincial Key Platform and Research Project) Project Number: 2015GXJK184

2. Fu Jingchuan. Drive mechanism of accelerating the establishment of original innovation in Zhu Hai (Zhuhai, The 2015 Social Science Planning Project) Project Number: 2015YB019 that civil-run colleges must rise to and demand a quick solution.

II. The TRANSFORMATION DEVELOPMENT OF GENERAL COLlEGES DURING THE PERIOD OF "13TH FIVE-YEAR PLAN" CANNOT Be Possible Without THE ESTABLISHMENT OF APPLICATION-ORIENTED UNIVERSITIES

\section{A. This Follows the Development Law of Higher Education}

The period of " $13^{\text {th }}$ Five-year Plan" is not only critical to building a moderately prosperous society in China, which also decides the Chinese modernization of education ${ }^{1}$. The 2015 Statistical Communiqué of Education Development reveals that total enrollments in various forms of higher education across the nation hit 36.47 million, the gross enrollment rate of higher education reached $40.0 \%{ }^{2}$, which marks the advancement of established target in "National Medium and Long-Term Program for Education Reform and Development (2010-2020)", but there is still a long way to the established target of "achieving the modernization of education, forming a learning-oriented society, and thronging into the first-tier human resources powers".

In addition to the enrollment rate, the modernization of higher education is also reflected in the enhancement of education philosophy and recognition of function. As for a college, the further optimization of education system and the formation of characteristics means abandoning the previous large and comprehensive model that was used by many colleges, but developing the featured model adapting to the economic and social development needs and benefiting its own sustainable growth. According to the development theory of higher education, the higher education development should be divided into three stages: "Elite Higher Education", "Mass Higher Education" and "Universal Higher Education" ${ }^{3}$, Notably "Universal Higher Education" is marked when the gross enrollment rate is $50 \%$ higher. At this stage, the type and standard of colleges tend to be diversified, the talent development target for colleges is

\footnotetext{
1 "Notice on Properly Preparing the Education Development during the " $13^{\text {th }}$ Five-year Plan" issued by General Office of Ministry of Education

2 The 2015 Statistical Communiqué of National Education Development 3 Gu Mingyuan. Great Encyclopedia of Chinese Education. P339-340
} 
more socialized, the teaching quality criteria and scientific research criteria will be mainly based on value addition, the boundary between school and society will gradually disappear, and the common characteristics among schools and specific characteristics are counteractive with each other.

Whether for a high-level university or a local college (including civil-run college), it must follow the basic law of higher education development in the course of achieving the modernization of higher education. The objective and orientation for modernization of higher education can be traced back to the 2010 "National Medium and Long-Term Program for Education Reform and Development"; in the first year during the period of " $13^{\text {th }}$ Five-year Plan", or on October $21^{\text {st }}$ of 2015, the Ministry of Education, The Development and Reform Commission, and the Ministry of Finance jointly issued the "Guideline on Instructing the Transformation of Local General Colleges to Applicationoriented Universities" (Jiao Fa No. [2015]7), which specifies the guiding ideas on establishment of application-oriented universities, and deploys and drives the transformation development of general colleges in an all-around manner. This document along with "Circular of the State Council on Printing and Distributing the General Program for Promoting World-Class Universities and First-class Disciplines" has become the directive standard for modernization of higher education during the period of " $13^{\text {th }}$ Five-year Plan".

In Guangdong, the gross enrollment rate of higher education was about $33 \%$ in $2015^{4}$. However, this deviates a lot from any other economically affluent area in terms of the scale or the overall level of higher education, incomparable to its economic status, more efforts should be pooled to achieve the goal of "modernization of higher education" during the period of " $13^{\text {th }}$ Five-year Plan". During the past " $12^{\text {th }}$ Five-year Plan", Guangdong began to implement the "Innovation-driven Schools Project", deepened the reform of higher education, streamlined administration and delegated power, encouraged innovation, and made remarkable achievements. During the period of " $13^{\text {th }}$ Five-year Plan", "Innovation-driven Schools Project" will become one of the core parts of Guangdong higher education reform, according to "Guangdong Overall Program for Higher Education 'Innovation-driven Schools Project' during the Period of ' $13^{\text {th }}$ Five-year Plan' (Trial)", the majority of general colleges and civil-run colleges will transform to "application-oriented colleges", the "Guangdong General Pilot Colleges for Education Transformation" has been established among some undergraduate colleges with good foundation, some advantages and characteristics, which accumulates experience and performs its role model effect, in order to achieve the goal of "accelerating the construction of higher education province, building the education height in South China." 5

\footnotetext{
$42016 \quad$ Guangdong Statistical Yearbook. http://www.gdstats.gov.cn/tjnj/2016/directory/content.html?18-01

5 Yue Jiao Gao (2016) No.6 Guangdong Overall Program for Higher Education "Innovation-driven Schools Project" during the Period of "13th Five-year Plan" (Trial) issued and printed by Guangdong Provincial Department of Education
}

\section{B. This Reflects the Concept of Higher Education Classification Management}

With the continuous development of higher education modernization, the type and standard of schools tend to be diversified, and therefore, it is evitable to implement the classification management according to the nature and characteristics of colleges. "National Medium and LongTerm Program for Education Reform and Development (2010-2020)" clearly states that "colleges should establish the classification system and implement the classification management". ${ }^{6}$ In "Guangdong Medium and Long-Term Program for Education Reform and Development (20102020)" also states "colleges should make a scientific orientation and give classification guidance. Improve the classification orientation and guidance of colleges. Establish the mechanism adapting to the classification orientation, classification guidance, classification development and classification development of colleges, exploit the role of policies in guidance and allocation of resources, and promote the scientific orientation of colleges ${ }^{7}$ ". During the period of " $13^{\text {th }}$ Five-year Plan", higher education will transform from homogenous development to differentiated development, which is an important implementation stage for the classification management reform of higher education. During the transformation development, civil-run colleges will be given two choices: first, the transformation under the classification management of research-oriented universities and application-oriented universities; second, the transformation of profit schools and non-profit schools in civil-run higher education.

Taking Guangdong for example, "Guangdong Overall Program for Higher Education 'Innovation-driven Schools Project' during the Period of ' $13^{\text {th }}$ Five-year Plan'" clearly states the basic principle of adhering to the classification guidance in college management. This Program takes an integrated account of school-running level, type and establishment objective for various colleges, defines four establishment types: "high-level university", "high-level science and engineering college", "application-oriented college", and "vocational college", incorporates local publicrun general college and civil-run college into the unified management of application-oriented colleges, and firstly implements the classification management by the target orientation of school instead of public or civil attributes.

With respect to the civil-run education, classification management should differentiate profit level from non-profit level, according to the latest "Civil-run Education Promotion Law of the People Republic of China", whether the organizer seeks reasonable returns or not, civil-run education belongs to the public welfare causes and comprises the socialist

6 Central People's Government of the PRC. National Medium and LongTerm Program for Education Reform and Development (2010-2020) [EB/OL] http://www.gov.cn/jrzg/2010-07/29/content_1667143.htm.201007-29.

7 People's Government of Guangdong Province. Notice on Printing and Issuing the Guangdong Education Development during the "12th Five-year Plan". http://zwgk.gd.gov.cn/006939748/201111/t20111118_292717.html.201111-07. 
education causes. However, there are still some differences between profit civil-run colleges and non-profit civil-run colleges with respect to the public welfare of school-running and the equity of resource allocation, the profit civil-run college primarily meets the needs of individualized education among special groups, while the non-profit civilrun college performs the basic duties as a university in the substantially same way as public college. Once a civil-run college chooses non-profit school-running, it is justified to enjoy the same rights and interests as public college in respect of legal and social status, rights and interests of teachers and students, and fiscal and taxation policies. All six civil-run colleges listed in "Guangdong General Pilot Colleges for Education Transformation" have chosen the public welfare-based school-running, which fully reflects the resolution of Guangdong Province in enforcing the classification management reform of civil-run education and implementing the classification management of higher education from the social value of colleges.

\section{This Reflects the Needs of Guangdong Economic Transformation for Application-oriented Universities}

Derek Curtis Bok, the President of Harvard University, mentioned in his book Universities and the Future of America "developed countries are increasingly dependent on three factors: new inventions, well-trained talents and expertise ${ }^{8}$." Universities are the main source that provides these three elements, application-oriented universities guarantee the supply of intellectual support and human resources for local innovation-driven development.

Innovation-driven strategy, as the development theory which should be adhered for a long time, is the core guiding idea of economic structure transformation and upgrading in New Normal. Its achievement of intensive growth depending on the innovation of scientific technologies and urgent demand for application-oriented talents will lead to the rapid development of application-oriented universities. The primary feature of application-oriented university is to be local-centered and directly combined with production to improve the labor productivity by rapidly converting new inventions; the development of application-oriented talents is the essential way of addressing the structural imbalance of talent supply and demand. The transformation and upgrading of local economic structure have posed new requirement for scientific innovation and human resources, which serves as the external impetus to the establishment of applicationoriented universities.

Guangdong standing at the forefront of reform and opening up has always led the innovation-driven strategy. The General Secretary Xi Jinping once earnestly instructed "Guangdong is an economic power, its regional GDP and restructuring should support the nation, it must lead the strategic adjustment of economic structure and act as the major force of innovation-driven development." To better serve the innovation-driven strategy, one of the important tasks for Guangdong higher education reform is to comprehensively promote the establishment of applicationoriented universities, which not only vigorously supports the transformation of public colleges to application-oriented universities, but also exploits the civil-run colleges as the impetus to implementing innovation-driven strategy. Under the guidance of "Innovation-driven Schools Project", the policy for general colleges changes from "approve all things for civil-run colleges, give differentiated treatment to civilrun colleges' to the policy-led under the overall plan and coordination and innovation encouragement; resource allocation changes from the fragmented project-led cake division to the cake-making model that encourages and supports independent innovation, and fully mobilizes colleges to proactively transform to application-oriented universities which is more flexible and fully implements the concept of innovation-driven development.

\section{This Affirms the Value of Civil-run Colleges}

Along with the revision of "Civil-run Education Promotion Law of the People's Republic of China", the previous embarrassment of civil-run higher education has gradually gone, under the guidance of innovation-driven strategy, civil-run colleges and public colleges have been the innovation drive for local economic and social development. In particular, the issuance of "Guangdong General Pilot Colleges for Education Transformation" demonstrates that Guangdong higher education is more mature and practical to the great satisfaction of organizers, teachers and students of civil-run colleges.

In the course of application-oriented universities established by civil-run colleges, the degree of regional economic development is the key factor, and regional economic development is the direct motive. The flourishing development of Guangdong civil-run higher education cannot be possible without the developed economic level and mature industrial base of Guangdong, especially without the vigorous support of Guangdong local government and people. The social attributes of civil-run colleges determine its close association with regional economy, and civil-run colleges must adapt themselves to the specific environment of regional economy. On the one hand, they should rapidly expand their scale and strength and supply a large number of application-oriented talents in need for the region, and proactively promote the transformation development of related industries with distinct regional characteristics, depending on local economic advantages; on the other hand, regional economic development facilitates the progress of application-oriented universities established by state-run colleges, after the course of exploration, attempt and reference to the experiences of developed countries and regions, they should gradually form the diversified and featured development pattern. 


\section{Civil-RUn Colleges Show TheIR AdVANTAGES IN ESTABLISHING APPLICATION-ORIENTED UNIVERSITIES}

\section{A. Marked Demand-oriented Establishment o Application- oriented Disciplines}

Discipline establishment of civil-run colleges is generally market-oriented. Civil-run colleges often choose the application-oriented disciplines in urgent social needs, with good employment prospect, as a sensitive and rapid response to social demand. Furthermore, they are good at seizing policy opportunities and market opportunities to promptly make innovation and reform, rapidly fine-tune the strategic decision, rapidly respond to social needs, and keenly capture the market information, with good adaptability. In addition, state-run colleges actively explore the joint development program with enterprises, order-based talent development, collectively establish the education mechanism, adhering to the school-running goal of meeting social needs, tailor "products" and "services" based on social requirement, and closely fit with the regional economy. These are distinct features and inherent advantages of the application-oriented universities established by civil-run colleges.

\section{B. Strengthen the Employment-centered Improvement of Practical Ability}

The effective solution to graduate employment concerns is the important goal for establishment of applicationoriented universities, it is more active and explorative to make a survival due to intensified competition among civilrun colleges, mounting survival pressure, and the strong sense of crisis, and they often treat the high-quality employment rate as the school-running lifeline. According to the actual needs of employers, civil-run colleges should place more emphasis on development of student practical ability and professional application ability. In terms of schooling system, they generally arrange " $3+1$ " (3-year professional study plus 1-year social practice); in terms of course system, they increase the ratio of practical course, invest in a lot of labs, actively cooperate with enterprises to build the practice bases, offer adequate practice opportunities for students, and enable students to be familiar with and capable of job contents upon graduation.

\section{Efficient and Practical Teachers}

Because civil-run colleges are "non-financially supported" units, they have a high degree of autonomy and flexibility in personnel policy: firstly, youths prefer more relaxed workplace and broader potentials; secondly, the "application-oriented" personnel system and individualized high-level talent policy have attracted disciplinary experts and scholars to make scientific innovation and give instructional guidance; thirdly, civil-run colleges could boldly appoint mangers or engineering talents from enterprises or production lines as disciplinary teachers, from the perspective of practical instructions. Teachers in civil-run colleges tend to be diversified, which can attract excellent managers and first-line professional technicians to participate in teaching, comprise the important component of "double- qualified" teachers, and guarantee the supply of teachers for development of application-oriented talents.

\section{Scientific Researches Serve Enterprises and Industries}

Subject to limitation of school-running conditions and influence of concept and policy, it is very hard for civil-run colleges to make high-level and high-grade scientific researches. On the one hand, it promotes scientific researchers in civil-run colleges to focus on serving enterprises and industries, and make scientific researches in civil-run colleges more suitable to industrial needs, which is more applicable. Scientific organization and management in civil-run colleges often adopt the method of collaborative innovation and integration of production and teaching, teacher will directly get involved in the production research and development, and students are motivated to take an part in scientific research projects and activities, which not only creates economic benefits for enterprises, but also benefits teaching through scientific research, enhance the teaching application, improve the innovation ability of students, ultimately enable teachers and students to strengthen the knowledge base and improve their ability during the scientific innovation.

\section{SEVERAL KeY POINTS FOR THE TRANSFORMATION OF CIVIL-RUN COLLEGES TO APPLICATION-ORIENTED UNIVERSITIES}

During the period of " $13^{\text {th }}$ Five-year Plan", Guangdong will vigorously push forward the establishment of application-oriented universities, which is an important change of the external development environment for civilrun colleges, and accordingly, civil-run colleges should also actively adapt to the new trend through connotation establishment, pool its efforts to create a new scene, and internally and externally drive the new scene of innovationdriven development. In the course of transformation development of civil-run colleges, what and how to transform should be deeply considered and constantly discussed.

\section{A. Change the Concept of School-running from Teaching- centered to Social Services}

Subject to the external environment and funding, the ratio of students to teachers just meets the teaching needs for a long term, which causes the actual operation of civil-run colleges to primarily center on teaching, and scientific research of teachers in a weak status. The lack in scientific research not only limits the innovation ability and development potentials of teachers, but also makes the actual contribution of scientific innovation by civil-run colleges below that by public colleges. In general, talent development only meets the social demand for high-quality laborers, while the social demand especially business demand for scientific innovation should be based on application-oriented scientific research. As scientific technology is the primary productive force, the subsequent development of civil-run colleges will be decelerated if they fall short of it. Since the adoption of innovation-driven strategy in Guangdong, the social demand especially business demand for scientific innovation is 
growing, the government pools greater efforts in scientific innovation, those civil-run colleges which are based in serving local economic and social development will be unable to fulfill such needs, which means that the competitiveness of civil-run colleges cannot be enhanced, and the scientific innovation resources of teachers will be seriously wasted.

At present, the state is vigorously promoting the supplyside structural reform, which is intended to improve the adaptability and flexibility of supply structure for changes of demand, improve the total factor productivity, and promote the sustainable healthy economic and social development. As for the social and business demand for scientific innovation, the supply potentials of civil-run college teachers for scientific research are enormous, which needs to be exploited in terms of concept, system and action, needs to start with the improvement of scientific research supply quality, facilitate the restructuring, increase the effective supply of application-oriented universities for social service, and exploit all its potentials. In addition, with a view to the development of teachers, teaching and scientific research are complementary, anyone who is solely immersed in classroom teaching will be far away from the forefront of scientific innovation, only by taking in more expertise from innovation practice, accumulating more experience, and improving ability could they benefit the teaching and develop the genuine high-quality application-oriented talents.

By now, civil-run colleges must change the concept of school-running, deepen the supply-side reform of social services, make transformation from teaching-oriented to improvement of social service ability, orient on economic and social demand, provided with the assured quality of talent development, vigorously develop the applicationoriented scientific research, and motivate teachers to actively get involved in scientific innovation. In the long run, local economic and social development served by scientific innovation will become a new growth point in the course of transformation development of civil-run colleges, only by improving the scientific innovation ability could civil-run colleges take in more resources from the society and obtain greater support from the government and enterprises. Only by exploiting all its potentials and fully meeting the social needs could civil-run colleges demonstrate stronger competitiveness and gain a better prospect.

\section{B. Change the Way of Talent Development from Knowledge Transfer to Development of Innovation Ability}

The development of application-oriented talents focuses on the all-around student development involving "basic knowledge, potential capacity, character quality, and sense of responsibility". The conventional knowledge transfer, even the infusive education model can hardly meet the needs of application-oriented talent development. In this concern, it is necessary to change the way of talent development, pay more attention to the development of innovation consciousness, entrepreneurship and innovative enterprise ability. Civil-run colleges need to start with the innovation and entrepreneurship education reform, strengthen the development of practical ability, introduce the talent quality standard recognized by enterprises and industries, and actively seek the possibility of establishing the collaborative education platform with enterprises.

Firstly, integrate innovation and entrepreneurship education with professional education. Achieve three $100 \%$ full coverage (innovation and entrepreneurship education course, extracurricular practice, practical training) in a planned way by revising the talent development program, implementing the credit system reform, and fully incorporating the modern information technology into teaching and taking other specific measures. Strengthen the innovation and entrepreneurship practice, select the primary demand of industrial enterprises as the topic of graduation thesis (or graduation design), actively establish the platform and guarantee mechanism of innovation and entrepreneurship practice, and connect all processes ranging from classroom teaching, practice and hands-on training to entrepreneurship incubation.

Secondly, actively introduce the discipline certification system, and enhance the core competitiveness of applicationoriented talents. Actual industrial and business demand is an indicator for application-oriented talent development as well as an important guarantee for high-quality employment. Discipline certification is the business and industrial requirement for standardization of talent development, which is often associated with occupational qualification and occupational registration system. The organic connection between school education and social demand during the certification can standardize professional talent development objective, course system and quality standard, which is an important starting point of promoting the disciplinary construction.

Thirdly, accelerate the establishment of collaborative education platform, and implement the reform from single subject of school to school-enterprise collaborative talent development. State-run colleges and local enterprises and utilities should collaboratively make the talent development program, collaboratively implement the teaching construction and talent development, achieve "collective talent development and win-win result", and ensure discipline development meet the business and industrial needs. Strengthen the construction of school-enterprise base, integrate the school education environment based on transfer of theoretical knowledge and basic skill training, and the production site environment based on production process knowledge, experiential knowledge and comprehensive application ability with the development process of students, and establish the mutually beneficial win-win cooperation mechanism.

\section{Change the Form of Scientific Research from Academic- led to Innovation Application}

Without the available conditions of carrying out scientific researches in academic research frontier and basic disciplines, the conventional academic-led research form cannot fulfill the actual social needs within a certain period. Therefore, civil-run colleges must find another alternative to exploit their advantages and characteristics, and incorporate into the 
scientific innovation activities in urgent market demand as early as possible. The sensitivity and effective grip of civilrun colleges on social needs and market opportunities, and the younger generation of faculty team make it necessary for civil-run colleges to break the conventional model, carry out the targeted and creative scientific researches, and provide talents and intelligence services for the benefit of local scientific innovation.

In addition to the exploitation of advantages and characteristics, the scientific innovation of civil-run colleges cannot be possible without a good cooperation established with the innovation-driven subject - Enterprise. Actively incorporate into the regional technological innovation system, orient at addressing the actual problems, improve the application-oriented technological services, pool greater efforts to collaboratively build research institute and public technological service platform with enterprise, actively dock with the innovation vehicles including industrial parks, professional towns and innovation and entrepreneurship parks, form and participate in industrial technology innovation alliance and technology $R \& D$ center, and establish the technological innovation association that is closely combined with regional industries and business features.

\section{Change the Faculty Structure from Academic-oriented to Double-qualified Teachers}

Teachers involved in developing application-oriented talents should demonstrate a higher academic level, with a wealth of practical experience and practical instructional competence. The faculty team of civil-run colleges is generally polarized, where the young and elderly teachers are the majority, but the middle-age key teachers are less. Although this situation is difficult to change in a short time, it is not necessarily the deficiency of civil-run colleges. On the contrary, the combination of youths' innovation ability and elderly teachers' abundant experience could play a crucial role in teaching and research. The aging structure cannot be altered in a short time, but in the course of establishing application-oriented universities, individual knowledge ability structure will be the key to determining the success of transformation development.

The development of application-oriented talents and technological innovation cannot be possible without an application-oriented faculty team, the state and Guangdong guideline on establishing application-oriented universities explicitly states that "double-qualified" faculty team should be actively built, in which "double-qualified" is the fundamental characteristic of application-oriented faculty team. Civil-run colleges should make full use of their autonomy and flexibility in personnel system. On the one hand, firstly select the professional technicians and managers with business background and practical experience, appoint them to act as the full-time or part-time teachers for disciplinary and practical course, break the recruitment limitation of academic degree of professional title for exceptionally outstanding talents, but focus on the assessment of practical competence. On the other hand, actively select youths or middle-aged teachers to participate in professional practices at enterprises, with access to the advanced production technologies and processes, know the industrial development trend, strengthen the practical ability, and establish the sustainable long-term training mechanism for youths and middle-aged teachers.

Certainly, with a view to the preponderant disciplines and featured subjects, civil-run colleges should still attract the discipline leaders, actively build the faculty team, maintain their advantages and keep progressive. From the sustainable development of faculty team, civil-run colleges must strengthen the classification building of faculty team, and form the faculty team with definite classification and smooth connection among discipline leaders, key teachers and double-qualified teachers.

\section{CONCLUSION}

According to the latest revision of "Civil-run Education Promotion Law of the People's Republic of China", the internal and external environment of non-profit civil-run colleges will be significantly improved: on the one hand, all school income will be used for its own development, which guarantees the adequate funds required for transformation development and the sustainability of development at the system level; on the other hand, governments will give more supports for civil-run application-oriented universities; in addition, with the deepening cooperation between civil-run colleges and enterprisers, the investment in school resources will be greater. Given a rare opportunity, civil-run colleges must make full use of these resources, exploit their advantages and characteristics, and seek a pathway of transformation development that truly incorporates into the local innovation-driven strategy.

\section{REFERENCES}

[1] Tao Yongmei and $\mathrm{Hu}$ Xingqi. Risk and pathway of the transformation of civil-run colleges to application-oriented technology universities, 2015(3) :135-137.

[2] Association of Universities (Colleges) of Applied Science. Research Report on Development Practices and Policies of the Transformation Development of Local Colleges [DB/OL]. http: / gjs.xxu.edu.cn/info/1011 / 1075.htm.

[3] Zhang Letian. Consideration on reopening of education reform agenda [J]. Fudan Education Forum, 2013 (3): 5-9.

[4] Wu Kangning. Understanding "Deepening the comprehensive education reform" $[\mathrm{J}]$. Research On Education Tsinghua University, 2013 (1): 8. 